\title{
On the linkage between tropospheric and Polar Stratospheric clouds in the Arctic as observed by space-borne lidar
}

\author{
P. Achtert, M. Karlsson Andersson, F. Khosrawi, and J. Gumbel \\ Department of Meteorology, Stockholm University, Stockholm, Sweden
}

Correspondence to: P. Achtert (peggy@ misu.su.se)

Received: 31 October 2011 - Published in Atmos. Chem. Phys. Discuss.: 7 December 2011

Revised: 4 April 2012 - Accepted: 9 April 2012 - Published: 25 April 2012

\begin{abstract}
The type of Polar stratospheric clouds (PSCs) as well as their temporal and spatial extent are important for the occurrence of heterogeneous reactions in the polar stratosphere. The formation of PSCs depends strongly on temperature. However, the mechanisms of the formation of solid PSCs are still poorly understood. Recent satellite studies of Antarctic PSCs have shown that their formation can be associated with deep-tropospheric clouds which have the ability to cool the lower stratosphere radiatively and/or adiabatically. In the present study, lidar measurements aboard the Cloud-Aerosol Lidar and Infrared Pathfinder Satellite Observation (CALIPSO) satellite were used to investigate whether the formation of Arctic PSCs can be associated with deeptropospheric clouds as well. Deep-tropospheric cloud systems have a vertical extent of more than $6.5 \mathrm{~km}$ with a cloud top height above $7 \mathrm{~km}$ altitude. PSCs observed by CALIPSO during the Arctic winter 2007/2008 were classified according to their type (STS, NAT, or ice) and to the kind of underlying tropospheric clouds. Our analysis reveals that 172 out of 211 observed PSCs occurred in connection with tropospheric clouds. $72 \%$ of these 172 observed PSCs occurred above deep-tropospheric clouds. We also find that the type of PSC seems to be connected to the characteristics of the underlying tropospheric cloud system. During the Arctic winter 2007/2008 PSCs consisting of ice were mainly observed in connection with deep-tropospheric cloud systems while no ice PSC was detected above cirrus. Furthermore, we find no correlation between the occurrence of PSCs and the top temperature of tropospheric clouds. Thus, our findings suggest that Arctic PSC formation is connected to adiabatice cooling, i.e. dynamic effects rather than radiative cooling.
\end{abstract}

\section{Introduction}

During late winter and early spring polar stratospheric clouds (PSCs) provide the surface for heterogeneous reactions which transform stable chlorine and bromine species into their highly reactive ozone-destroying states. Therefore, PSCs are important for ozone depletion during winter at high latitudes. The formation of PSCs depends strongly on temperature. PSCs are classified into three types according to their particle composition and to their physical phase (McCormick et al., 1982; Poole and McCormick, 1988). PSCs of type Ia and Ib form at temperatures below 195 K. PSCs of type Ia are composed of nitric acid di- or trihydrate crystals (NAD, NAT) (Voigt et al., 2000; Stetzer et al., 2006), while those of type $\mathrm{Ib}$ include supercooled liquid ternary solutions (STS) that consist of $\mathrm{H}_{2} \mathrm{SO}_{4}, \mathrm{HNO}_{3}$, and $\mathrm{H}_{2} \mathrm{O}$ (Carslaw et al., 1994). In contrast, PSCs of type II are formed below the ice-frost point and consist of pure-water ice particles (Poole and McCormick, 1988). All PSCs that cannot be clearly classified by optical measurements are referred to as mixedphase clouds composed of both solid and liquid particles (Shibata et al., 1999; Biele et al., 2001).

In the Arctic stratosphere, the formation of PSCs is strongly controlled by the detailed structure of the temperature profile. Previous studies (Carslaw et al., 1998; Dörnbrack et al., 2000; Höpfner et al., 2006; Blum et al., 2005; Juarez et al., 2009) concluded that Arctic PSCs are mostly formed due to gravity-wave-induced temperature modifications. Recent studies showed that gravity-waveinduced temperature modifications are also important for Antarctic PSCs formation in early winter when synoptic processes are not sufficient for producing the temperatures necessary for PSC formation (Höpfner et al., 2006; Eckermann et al., 2009; McDonald et al., 2009). However, Wang et al. (2008) showed that during the period June-October 2006 
$66 \%$ and $52 \%$ of the PSCs over western and eastern Antarctica, respectively, were associated with an underlying deeptropospheric cloud systems. Furthermore, Cariolle et al. (1989), Carslaw et al. (1998), and Teitelbaum et al. (2001) showed that local cooling in the lower stratosphere can be caused by synoptic or mesoscale tropospheric events. This cooling effect can affect both PSC formation and microphysical properties, i.e., PSC type (Adhikari et al., 2010).

Ground-based lidar measurements can provide continuous observations with high temporal and vertical resolution for investigating the occurrence and composition of PSCs as well as for evaluating microphysical model simulations (Daneva and Shibata , 2003; Adriani et al., 2004; Blum et al., 2005, 2006; Jumelet et al., 2008a,b; Achtert et al., 2011; Khosrawi et al., 2011). However, ground-based lidar measurements are restricted to distinct locations and strongly dependent on favorable tropospheric weather conditions (i.e., the absence of tropospheric clouds). Space-borne lidars like the one on the CALIPSO (Cloud-Aerosol Lidar and Infrared Pathfinder Satellite Observation) satellite are able to perform measurements with a high vertical resolution independent from the weather situation in the troposphere. However, a certain geographic location is only covered after a specific time period. In case of CALIPSO this return cycle is 16 days. Luckily, this matter is of minor concern for observations at high latitudes where polar orbiting satellites provide a good spatial coverage.

The present study examines the possible relationship between the occurrence of Arctic PSCs and tropospheric clouds by using observations from the space-borne CloudAerosol Lidar with Orthogonal Polarization (CALIOP) aboard CALIPSO between December 2007 and February 2008. CALIPSO represents a perfect tool to provide a vortexwide perspective of PSCs, e.g. Pitts et al. (2011). The CALIPSO PSC observations were classified to investigate whether the PSC microphysical properties depend on the underlying tropospheric clouds.

This paper is structured as follows: First we will give a description of the data analyses in Sect. 2. Results are presented in Sect. 3. The paper closes with a discussion of our findings and conclusions in Sects. 4 and 5, respectively.

\section{Instrumentation and data analysis}

The space-borne lidar CALIOP aboard CALIPSO is a twowavelength (532 and $1064 \mathrm{~nm}$ ) lidar. CALIPSO profiles are provided on a non-uniform altitude and time grid (Winker et al., 2007) and are available from http://www-calipso.larc. nasa.gov/products/. For classification of the three PSC types we utilized a combination of the linear aerosol depolarization ratio $\delta_{\text {aer }}$ and the value of $1-1 / R$, both measured at $532 \mathrm{~nm}$ (Adriani et al., 2004; Massoli et al., 2006; Achtert et al., 2011). $R$ is the backscatter ratio which is defined as the ratio of total (aerosols and molecules) to molecular backscat- ter. Backscatter ratios of unity refer to an aerosol-free atmosphere while the contribution of aerosol increases with increasing $R$.

For our study we used CALIPSO data observed between $60^{\circ}$ and $83^{\circ} \mathrm{N}$ in the time period from December 2007 to February 2008. The level 1 attenuated backscatter product was used to detect and identify PSCs. A PSC is identified if the backscatter ratio $R$ is larger than 1.06 over three height bins. This threshold is identical to the one used for PSC classification with the Esrange lidar (Blum et al., 2005). To increase the signal-to-noise ratio only profiles including a PSC were considered for averaging. The same method was used in Achtert et al. (2011) for comparison of CALIPSO PSC observations to ground-based measurements with the help of backward trajectories and box-model calculations of the backscatter ratio along these trajectories. In this paper very good agreement was found between CALIPSO backscatter ratios within PSCs and the ones measured with the groundbased Esrange lidar.

In contrast to our approach Pitts et al. (2009) chose their detection threshold conservatively and depending on the averaging length without excluding PSC-free profiles. They state that their study is likely to represent the lower limit of true PSC coverage. The aerosol depolarization ratio is defined as the ratio of backscatter signal in the plane of polarization perpendicular and parallel to the one of the emitted laser light (Achtert et al., 2011).

To obtain meteorology information about underlying tropospheric clouds (e.g., cloud top height and cloud top temperature) the CALIPSO level 2 cloud and aerosol layer product (CAL_LID_L2_05km_CLay-Prov-V3-01) was used on a $5 \mathrm{~km}$ horizontal grid. The meteorological properties are derived from data provided by Global Modeling and Assimilation Office for every CALIPSO profile. The input data are GDAS (Global Data Assimilation System) output files with additional data from AIRS (Atmospheric Infrared Sounder) observations. More information are available at http://gmao.gsfc.nasa.gov/operations.

The attenuated backscatter ratio was used to detect PSCs and to identify the altitude range and the spatial extent of possible underlying tropospheric clouds. As suggested by Adhikari et al. (2010) tropospheric cloud conditions were classified into five different groups: cirrus (above $7 \mathrm{~km}$ height), deep-tropospheric clouds (more than $6.5 \mathrm{~km}$ in extent, cloud top height above $7 \mathrm{~km}$ ), mid-tropospheric clouds (below $7 \mathrm{~km}$ height), low clouds (at around $2 \mathrm{~km}$ height), and no clouds.

Figure 1 shows an example of a CALIPSO observation between 08:49 and 09:35 UTC on 2 January 2008 in terms of a time-height display of the attenuated backscatter coefficient. An inhomogeneous PSC (different optical characteristics and inferred composition) is visible in the color plot between 19 and $27 \mathrm{~km}$ height. This cloud can easily be identified in the profiles of the parallel and perpendicular backscatter ratios (Fig. 1c). All kinds of tropospheric clouds were present 


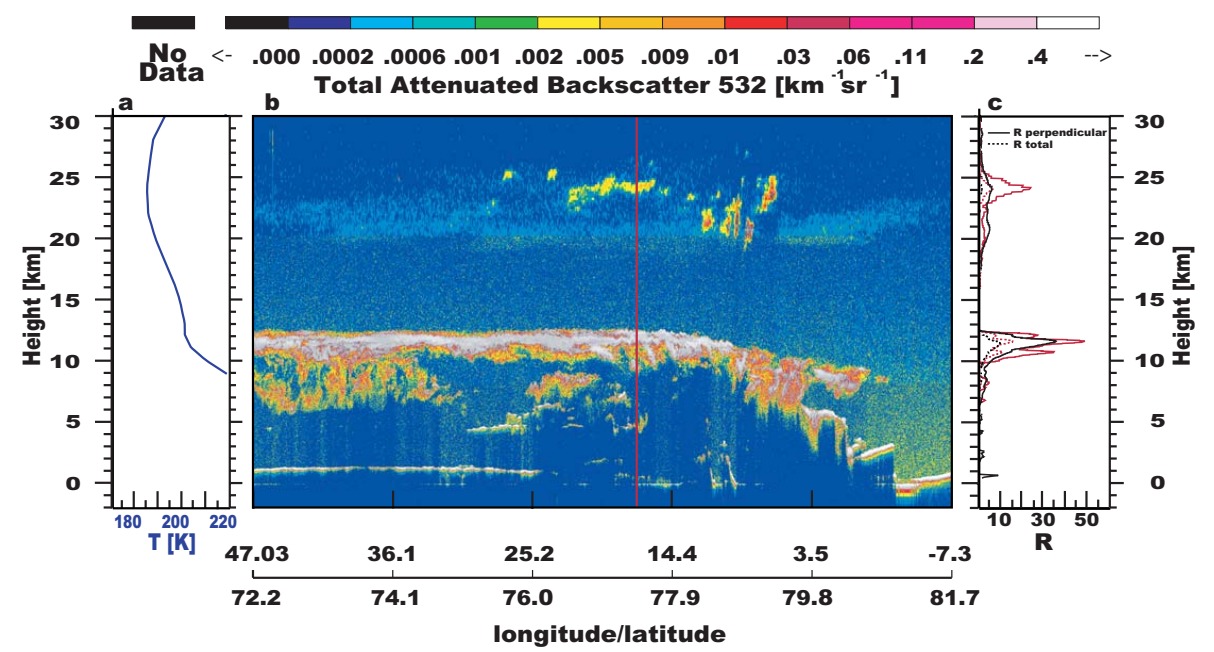

Fig. 1. Observation of an inhomogeneous PSC on the 2 January 2008 over an deep-tropospheric cloud system in terms of a time-height display of the attenuated backscatter coefficient at $532 \mathrm{~nm}$ as observed by the CALIPSO lidar between 08:49 and 09:35 UTC. (a) The mean stratospheric temperature over the longitude and latitude range of the observed PSC is shown on the left side. The red line in the total attenuated backscatter plot (b) shows an example for the mean position for the average calculation of the backscatter ratio. (c) The backscatter ratio perpendicular (red dotted line $1.5^{\circ}$ average, black dotted line $10^{\circ}$ average), and parallel (red solid line $1.5^{\circ}$ average, black solid $10^{\circ}$ average).

below the PSC in Fig. 1b: deep-tropospheric clouds between $72.2^{\circ}$ and $79^{\circ} \mathrm{N}$, cirrus and mid-tropospheric clouds between $79^{\circ}$ and $80^{\circ} \mathrm{N}$, low clouds between $80^{\circ}$ and $81^{\circ} \mathrm{N}$, and no clouds north of $81^{\circ} \mathrm{N}$. Different choices of along-track averaging intervals of the backscatter ratios (black and red lines in Fig. 1c) do not change the altitude range of the observed clouds. They, however, affect the resulting backscatter ratio, which might have an impact on the PSC classification. To prevent this, averaging intervals for the cloud classifications were decreased in case of varying properties within one PSC as was suggested by Pitts et al. (2011). The PSC shown in Fig. 1 was classified as mixed-phase PSC with STS, NAT, and ice layers according to the method of Massoli et al. (2006). A detailed view of this classification is shown in Fig. 2. The display of $1-1 / \mathrm{R}$ versus the aerosol depolarization ratio reveals a height-resolved view of the composition of the PSC observed in Fig. 1. The PSC observed on 2 January 2008 consists of several layers: some liquid and mixedphase particles exist below around $23 \mathrm{~km}$ height and above $25 \mathrm{~km}$ height. The particles in between these two altitude ranges are either mixed-phase particles or ice.

\section{Results}

During the arctic winter 2007/2008, the PSC formation temperature was first reached in the beginning of December. Minimum temperatures inside the vortex remained below the PSC formation threshold until late February 2008. Between 15 December 2007 and 6 February 2008 a total number of 211 PSCs could be identified from the CALIPSO lidar ob-

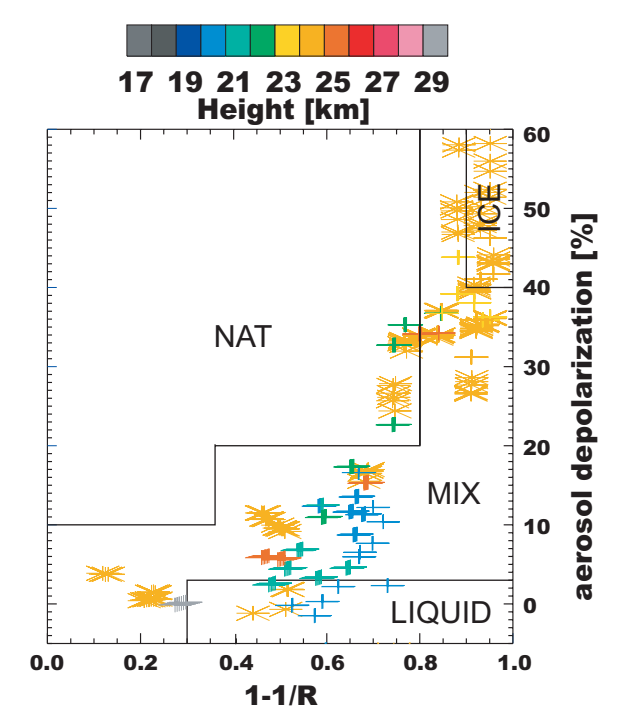

Fig. 2. PSC classification scheme for the inhomogeneous PSC observed on 2 January 2008 (see Fig. 1). The boundaries for NAT, Ice, mixed-particle, and STS PSCs are drawn into the plot as lines. The different colors and symbols represent the height of the PSCs

servations in the Arctic. A time-resolved display of these observations is given in Fig. 3a. These PSCs were analyzed with respect to their composition (Fig. 3b) and the type of underlying tropospheric clouds (Table 1). The highest number of PSCs was observed in early January 2008. Mixed-phase (47\%) and STS clouds (37\%) dominated during the period under investigation. Generally ice PSCs were rather rarely observed during that winter $(11 \%)$. NAT PSCs were mainly 
Table 1. Number of different tropospheric cloud types observed concurrent to the 211 PSCs detected by the CALIPSO lidar during winter 2007/2008. For comparison, the table also gives the number of deep-tropospheric clouds and low/no clouds for which no PSCs were observed.

\begin{tabular}{lccc}
\hline group & total number & $\begin{array}{c}\text { tropospheric cloudiness } \\
\text { when PSCs are present }\end{array}$ & $\begin{array}{c}\text { tropospheric cloudiness } \\
\text { no PSCs are present }\end{array}$ \\
\hline deep-tropospheric clouds & 124 & $58.8 \%$ & $28 \%$ \\
low/no tropospheric cloud & 39 & $18.5 \%$ & $41 \%$ \\
cirrus & 22 & $10.4 \%$ & \\
mid-tropospheric clouds & 26 & $12.3 \%$ & \\
\hline
\end{tabular}

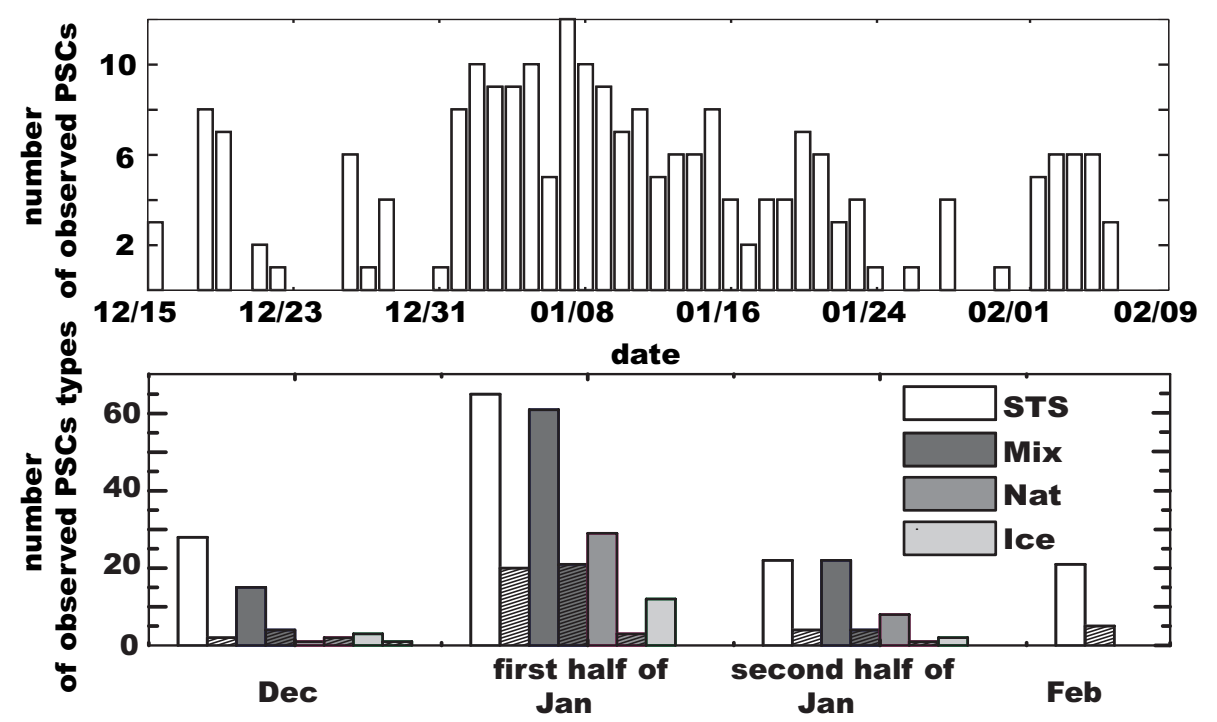

Fig. 3. (a) Daily resolved number of PSCs detected in CALIPSO measurements north of $60^{\circ} \mathrm{N}$ during winter 2007/2008. PSCs with a large spatial extent might be counted multiple times as they show up on subsequent CALIPSO tracks. CALIPSO passes the arctic every 100 min with about $25^{\circ}$ longitude shift between. (b) Analysis of the PSC observations in accordance to their type. Unshaded and shaded bars refer to observations over tropospheric clouds or during the absence of tropospheric clouds, respectively. The distribution differs from the display in (a) because individual PSCs might contain areas of different composition.

observed during January while February was dominated by pure STS clouds. Most of the observed PSCs were associated with a concurrent occurrence of tropospheric clouds. During the entire period ice PSCs were only once observed during the absence of tropospheric clouds (Fig. 3b, shaded light gray).

All 211 observed PSCs were classified and sorted into four different groups with respect to the underlying tropospheric cloud systems as described in Sect. 2. Table 1 resolves the connection between an observed PSC and the underlying tropospheric conditions. 172 out of the $211 \mathrm{ob}-$ served PSCs ( $81.5 \%$ of all cases) occurred in connection with tropospheric clouds. $72 \%$ of these 172 PSCs $(58.8 \%$ of all PSCs) were observed over deep-tropospheric cloud systems. 26 cases of PSCs were found over mid-tropospheric clouds (12.3\% of all cases) while 22 cases of PSCs were oberved over cirrus (10.4\% of all cases). The remaining 39 PSCs (18.5\% of all cases) showed an absence of tropospheric clouds. For comparison a deep tropospheric cloud without PSC occurred during $28 \%$ of all observations (considered CALIPSO over passes during the winter 2007/2008).

To reveal whether there is a connection between the type of a PSC and a specific type of underlying tropospheric cloud system, the PSCs observed over similar tropospheric situations (see Table 1) were also classified according to their composition as was shown in Fig. 2 for 2 January 2008. Figure 4 shows this classification for PSCs over cirrus (a), mid-tropospheric clouds (b), and an absence of tropospheric clouds (c). The large group of PSCs over deep-tropospheric clouds was further specified with respect to the overlap between the PSC and the tropospheric cloud layer. The lower panel in Fig. 4 therefore shows the relation between PSC composition and deep-tropospheric clouds for cases in which the observed PSC had the same (d) or a larger spatial extent (e) as the underlying deep-tropospheric clouds or in which the PSC was observed over a mixture of deep-tropospheric clouds and mid-tropospheric clouds (f).

PSCs observed during the absence of tropospheric clouds do not show a preferred type of PSC (Fig. 2c). Ice PSCs 

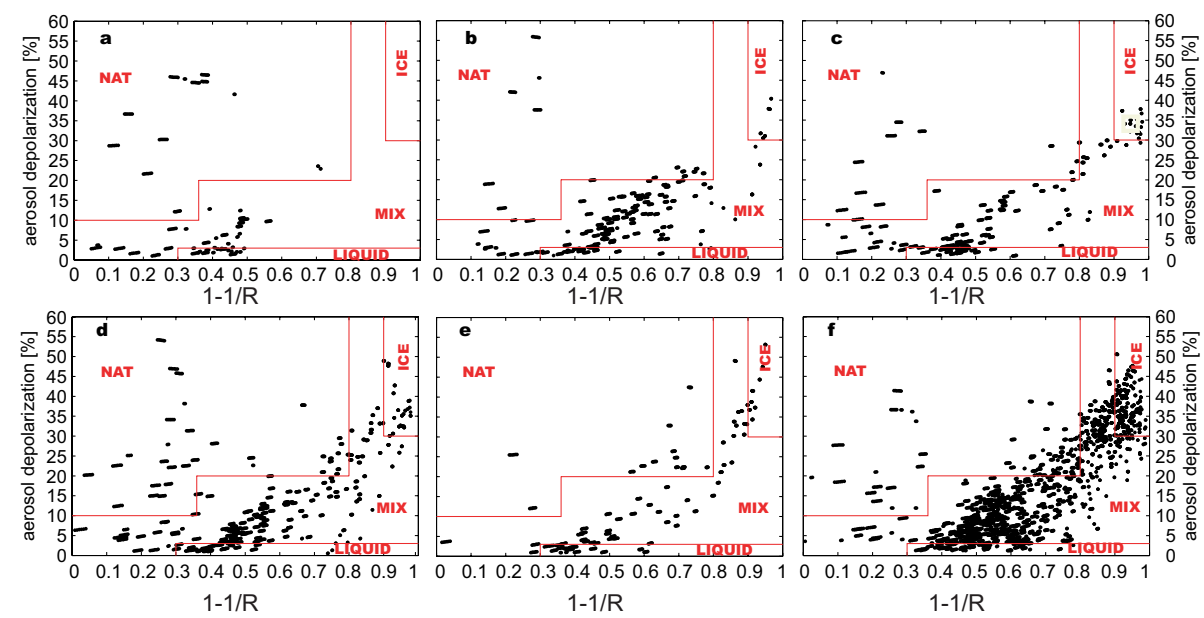

Fig. 4. PSCs detected by CALIPSO classified according to Massoli et al. (2006) with respect to the type of the underlying tropospheric cloud system: cirrus (a), mid-tropospheric clouds (b), and an absence of tropospheric clouds (c). Deep-tropospheric clouds were further distinguished with respect to the overlap between the PSC and the tropospheric cloud layer: PSC had the same (d) or a larger spatial extent (e) as the underlying deep-tropospheric clouds or the PSC was observed over a mixture of deep-tropospheric clouds and mid-tropospheric clouds (f). One dot represents one height bin (60 m vertical resolution, $180 \mathrm{~m}$ smoothing length ) of a CALIPSO profile.

were mostly observed when deep-tropospheric clouds where present. No ice PSCs were found, if cirrus was detected under the PSC. If PSCs were observed above mid-tropospheric clouds, they were mostly consisting of liquid or mixed-phase particles.

\section{Discussion}

Our analysis shows that the relative occurrence of different PSC types is related to the occurrence of deep tropospheric cloud systems. The deep tropospheric cloud systems may affect the PSC formation because of their ability to cause both radiative and adiabatic cooling in the lower stratosphere (Teitelbaum et al., 2001; Wang et al., 2008; Adhikari et al., 2010). According to Adhikari et al. (2010) the effect of additional cooling might be more important for ice particle formation than for STS formation due to the fact that lower temperature are required to form stratospheric ice particles. Fromm et al. (2003) showed that the average tropopause height in the Arctic associated with PSC observations is significant higher than that of clear sky observations. They conclude that PSC formation in the Arctic is dominated by synoptic-scale forcing. Simmonds and Keay (2000); Carrasco et al. (2003) observed a larger number of PSCs in the Antarctic in the downwind regions of intense mesoscale cyclogenesis. Deep tropospheric clouds are an indicator for the presence of large scale lifting and cyclonic activities (Teitelbaum et al., 2001). Teitelbaum et al. (2001) also reported a linkage between tropospheric synoptic-scale baroclinic waves and PSCs formation. Mountain wave generated PSCs can cover large areas and persist for long time, but they are quasi-stationary relative to the mean stratospheric flow (Cariolle et al., 1989) and therefore cannot explain monthly and interannual spatial variability of PSCs. Their findings suggest that the occurrence of PSCs is highly dependent on tropospheric dynamics rather than mountain generated small-scale waves. This is in agreement with our observations which show that $81.5 \%$ of the observed PSCs occurred over tropospheric clouds and thereof $72 \%$ over deeptropospheric clouds. During the winter 2007/2008 deep tropospheric clouds without PSCs occurred only during $28 \%$ of CALIPSO overpasses. PSCs investigated in this study were distributed over the entire Arctic (not shown). Most PSCs, were observed by CALIPSO south of Svalbard and in the Barents Sea. This suggests that the orographic influence (mountain generated small-scale waves) is rather small.

Cooling associated with the presence of tropospheric clouds has an impact on the microphysical properties of PSCs as is discussed by Adhikari et al. (2010). Their finding show that high and deep-tropospheric cloud systems have an significant effect on the relative occurrence of different PSC types, especially on ice PSCs. PSCs of the type ice and mix associated with cirrus and deep tropospheric clouds showed larger backscatter ratios compared to PSCs associated with no cirrus and deep tropospheric clouds. (Adhikari et al., 2010) concluded that this is due to an increase of the nucleation efficiency, providing a higher particle number concentrations. Our observations are in agreement with the findings by Adhikari et al. (2010). Figure 4d, e, f (associated with deep tropospheric clouds) shows larger number of observations with higher backscatter ratios compared to Fig. $4 \mathrm{c}$ which is associated with PSCs observation without underlying tropospheric clouds. In contrast to Adhikari et al. (2010) our study revealed no increased backscatter ratio within PSCs observed above cirrus clouds. 


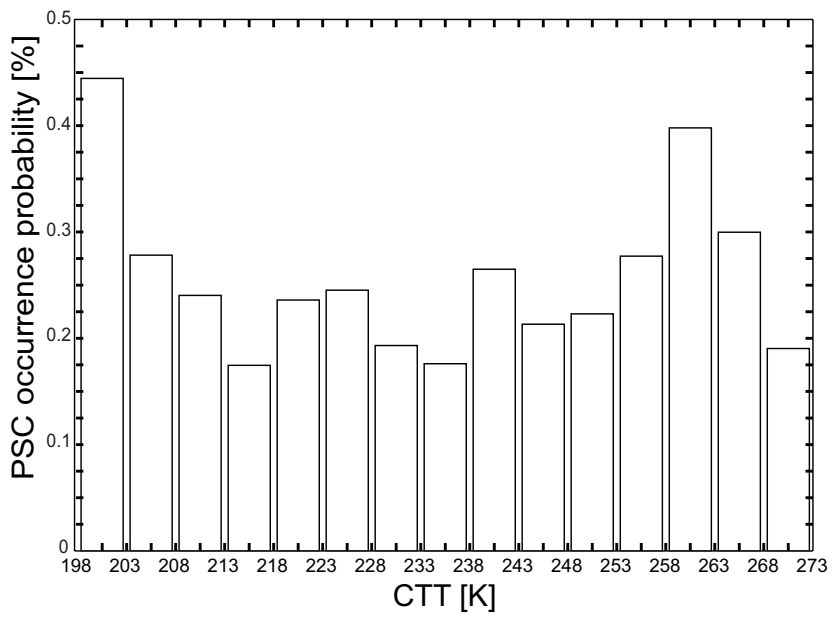

Fig. 5. Observed probability of PSC occurrence $\left(f_{\mathrm{PSC}}\right)$ with respect to the cloud top temperature (CTT) of all observed tropospheric clouds during the time period from December 2007 to February 2008 in steps of $5 \mathrm{~K}$.

We now investigate the available data, to check for possible indications of dynamic or radiative control of PSCs. Deep-tropospheric cloud systems are associated with largescale lifting and/or strong local convective and cyclonic activities. Wang et al. (2008) investigated the connection between PSC occurrence and tropospheric clouds in the Antarctic. They conclude that PSC occurrence is strongly linked to tropospheric dynamic and radiative cooling from the underlying tropospheric clouds. To investigate the possible radiative effect on PSC formation we derive the probability of PSC occurrence as a function of the cloud top temperature (CTT) of the underlying tropospheric clouds.

For this purpose, we extracted the CTT of the highest observed tropospheric clouds in each CALIPSO profile from the CALIPSO level 2 cloud and aerosol layer product during the time period from December 2007 to February 2008. The CTT determines the upwelling thermal radiation from the troposphere to the stratosphere, and thus a possible radiative control of the PSC occurrence. The occurrence probability $\left(f_{\mathrm{PSC}}\right)$ is defined as the ratio of the number of PSC observations and the total number of observations. $f_{\mathrm{PSC}}$ was calculated in CTT steps of $5 \mathrm{~K}$ and is presented in Fig. 5. Therefore, the numbers in Fig. 5 are very small. It can be seen from the figure that there is no correlation between the occurrence of PSCs and the top temperature of tropospheric clouds. If there was a significant radiative effect, a clear dependence of PSC occurrence should be visible.

\section{Summary and conclusions}

We investigated whether the formation of PSCs in the Arctic is associated with tropospheric clouds by using spaceborne lidar measurements from CALIPSO. Our investigation re- vealed a similar result as was shown in previous studies of Antarctic PSCs. In our Arctic study for the winter 2007/2008 we found that more than $80 \%$ of the observed PSCs between 15 December 2007 and 6 February 2008 occured in connection with tropospheric clouds. More than $58 \%$ of all PSCs were observed above deep-tropospheric clouds. More than $58 \%$ of all PSCs were observed above deep-tropospheric clouds. Together with the fact that we could not identify any correlation between PSCs and tropospheric cloud top temperature, this indicates that tropospheric control of PSC occurence is governed by adiabatic cooling connected to mesoscale cyclonic dynamics rather than by radiative cooling. Our findings corroborate the study of Teitelbaum et al. (2001).

Furthermore, the type of tropospheric cloud system below a PSC seems to affect the microphysical properties of the PSC above. This effect on the PSC properties seems to be most important for the formation of ice PSCs. In winter 2007/2008, ice PSCs were only once observed during the absence of tropospheric clouds. Since the ice formation temperature is rarely obtained in the Arctic, additional cooling is required. Adiabatically cooling above deep-tropospheric cloud systems might be the trigger for this process as shown in this study.

In a changing climate, storm tracks might get shifted polewards (Dethloff , 2004; Yin , 2005) and can therefore provide favorable conditions for the formation of ice PSCs. Dethloff (2004) reported a decrease of the geopotential height and an enhanced winter polar vortex as an influence of Greenland's deglaciation. Subsequently, ozone depletion and the possibility for an Arctic ozone hole would be increased. Simmonds et al. (2008) investigated the cyclonic behavior in the Arctic region. They conclude that the highest density of cyclones is found between Norway and Svalbard and further eastward in the Barents and Kara Seas. Furthermore, the highest rates of cyclogenesis is south of Svalbard and in the Barents Sea, were CALIPSO observed most PSCs.

Though the study presented in this paper is restricted to one Arctic winter a clear connection between tropospheric clouds and PSC occurrence could be established. Future studies which consider the entire CALIPSO data set (6 Arctic winters so far) would be very valuable to provide insight into the processes behind the observed connection.

Acknowledgements. CALIPSO data were obtained from the NASA Langley Research Center Atmospheric Science Data Center. We thank the CALIPSO science team for providing these data.

Edited by: D. Knopf 


\section{References}

Achtert, P., Khosrawi F., Blum U., and Fricke K. H.: Investigation of polar stratospheric clouds in January 2008 by means of ground-based and spaceborne lidar measurements and microphysical box model simulations, J. Geophys. Res., doi:10.1029/2010JD014803, 2011.

Adriani, A., Massoli P., di Donfrancesco G., Cairo F., Moriconi M., and Snels M.: Climatology of polar stratospheric clouds based on lidar observations from 1993 to 2001 over McMurdo Station, Antarctica, J. Geophys. Res., 109, doi:10.1029/2004JD004800, 2005.

Adhikari, L., Wang Z. and Liu D.: Microphysical properties of Antarctic polar stratospheric clouds and their dependence on tropospheric cloud systems, J. Geophys. Res., 115, D00H18, doi:10.1029/2009JD012125, 2010.

Blum, U., Fricke K. H., Müller K. P., Siebert J., Baumgarten G.: Long-term lidar observations of polar stratospheric clouds at Esrange in northern Sweden, Tellus, 57B, 412-422, 2005.

Blum, U., Khosrawi, F., Baumgarten, G., Stebel, K., Müller, R., and Fricke, K. H.: Simultaneous lidar observations of a polar stratospheric cloud on the east and west sides of the Scandinavian mountains and microphysical box model simulations, Ann. Geophys., 24, 3267-3277, doi:10.5194/angeo-24-3267-2006, 2006.

Biele, J., Tsias A., Luo B. P., Carslaw K. S., Neuber R., Beyerle G., and Peter T.: Non-equilibrium coexistence of solid and liquid particles in Arctic stratospheric clouds, J. Geophys. Res., 106, 22991-23007, 2001.

Cariolle, D., Müller S., and Cayla F.: Mountain waves, polar stratospheric clouds, and the ozone depletion over Antarctica. J. Geophys. Res., 94, 11233-11240, doi:10.1029/JD094ID09, 1989.

Carrasco, K. F., Bromwich D. H., and Monaghan A. J.: Distribution and characteristics of mesoscale cyclones in the Antarctic: Ross Sea east- ward to the Weddell Sea, Mon. Weather Rev., 131, 289301, doi:10.1175/1520-04932003131, 2003.

Carslaw, K. S., Luo B. P., Clegg S. L., Peter T., Brimblecombe P., and Crutzen P. J.: Stratospheric aerosol growth and HNO3 gas phase depletion from coupled $\mathrm{HNO}_{3}$ and water uptake by liquid particles, Geophys. Res. Lett., 21, 2479-2482, 1994.

Carslaw K. S., Wirth M., Tsias A., Luo B. P., Dornbrack A., Leutbecher M., Volkert H., Renger W., Bacmeister J. T., Reimers E., and Peter T. H.: Increased stratospheric ozone depletion due to mountain-induced atmospheric waves, Nature, 391, 675-678, 1998.

Daneva, D. and Shibata T.: The mixing state of polar stratospheric cloud particles in "sandwich structure" observed by lidar: 2 . Numerical simulations of the optical properties of liquid and solid particles with external mixture of STS and NAT particles, J. Meteorol. Soc. Jpn., 81, 759-777, doi:10.2151/jmsj.81.759, 2003.

Dethloff, K., Dorn, W., Rinke, A., Fraedrich, K., Junge, M., Roeckner, E., Gayler, V., Cubasch, U., and Christensen, J. H.: The impact of Greenland's deglaciation on the Arctic circulation, Geophys. Res. Lett., 31, doi:10.1029/2004GL020714, 2004.

Dörnbrack, A., Leutbecher M., Reichardt J., Behrend A., Müller K. P. and Baumgarten G.: Relevance of mountain wave cooling for the formation of polar stratospheric clouds over Scandinavia: Mesoscale dynamics and observations for January 1997, J. Geophys. Res., 106, 1569-1581, 2000.

Eckermann, S. D., Hoffmann L., Höpfner M., Wu D. L., and Alexander M. J.: Antarctic NAT PSC belt of June 2003: Ob- servational validation of the mountain wave seeding hypothesis Geophys. Res. Lett., 36, L02807, doi:10.1029/2008GL036629, 2009.

Fromm, M., Alfred, J., and Pitts, M.: A unified, long-term, highlatitude stratospheric aerosol and cloud database using SAM II, SAGE II, and POAM II/III data: Algorithm description, database definition, and climatology J. Geophys. Res., 108, 4366, doi:10.1029/2002JD002772, 2003.

Höpfner, M., Blumenstock, T., Hase, F., Zimmermann, A., Flentje, H., and Fueglistaler, S.: Mountain polar stratospheric cloud measurements by ground based FTIR solar absorption spectroscopy, Geophys. Res. Lett., 28, 2189-2192, 2001.

Höpfner, M., Larsen, N., Spang, R., Luo, B. P., Ma, J., Svendsen, S. H., Eckermann, S. D., Knudsen, B., Massoli, P., Cairo, F., Stiller, G., Clarmann, T. v., and Fischer, H.: MIPAS detects Antarctic stratospheric belt of NAT PSCs caused by mountain waves, Atmos. Chem. Phys., 6, 1221-1230, doi:10.5194/acp-6-1221-2006, 2006.

Juárez, M. D., Marcus S., Dörnbrack A., Schrøder T. M., Kivi R., Iijima B. A., Hajj G. A., and Mannucci A. J.: Detection of temperatures conducive to Arctic polar stratospheric clouds using CHAMP and SAC-C radio occultation data, J. Geophys. Res., 114, D07112, doi:10.1029/2008JD011261, 2009.

Jumelet, J., Bekki S., David C., and Keckhut P.: Statistical estimation of stratospheric particle size distribution by combining optical modeling and lidar scattering measurements, Atmos. Chem. Phys., 8, 5435-5448, doi:10.5194/acp-8-5435-2008, 2008a.

Jumelet, J., Bekki S., David C., Keckhut P., and Baumgarten G.: Size distribution time series of a polar stratospheric cloud event observed above Arctic Lidar Observatory for Middle Atmosphere Research (ALOMAR) $\left(69^{\circ} \mathrm{N}\right)$ and analyzed from multiwavelength lidar measurements during the winter 2005, J. Geophys. Res., 114, D02202, doi:10.1029/2008JD010119, 2008b.

Khosrawi F., Urban J., Pitts M. C., Voelger P., Achtert P., Kaphlanov M., Santee M. L., Manney G. L., Murtagh D., and Fricke K. H.:, Denitrification and polar stratospheric cloud formation during the Arctic winter 2009/2010, Atmos. Chem. Phys., 11, 84718487, doi:10.5194/acp-11-8471-2011, 2011.

Massoli, P., Maturilli, M., and Neuber, R.: Climatology of Arctic polar stratospheric clouds as measured by lidar in Ny-Ålesund, Spitsbergen $\left(79^{\circ} \mathrm{N}, 12^{\circ} \mathrm{E}\right)$, J. Geophys. Res., 111, D09206, doi:10.1029/2005JD005840, 2006.

McCormick, M. P., Steele, H. M., Hamill, P., Chu, W. P., and Swissler, T. J.: Polar stratospheric cloud sightings by SAM II, Atmos. Sci., 39, 1387-1397. 1982.

McDonald, A. J., George, S. E., and Woollands, R. M.: Can gravity waves significantly impact PSC occurrence in the Antarctic?, Atmos. Chem. Phys., 9, 8825-8840, doi:10.5194/acp-9-88252009, 2009.

Pitts, M. C., Poole, L. R., and Thomason, L. W.: CALIPSO polar stratospheric cloud observations: second-generation detection algorithm and composition discrimination, Atmos. Chem. Phys., 9, 7577-7589, doi:10.5194/acp-9-7577-2009, 2009.

Pitts, M. C., Poole, L. R., Dörnbrack, A., and Thomason, L. W.: The 2009/2010 Arctic polar stratospheric cloud season: a CALIPSO perspective, Atmos. Chem. Phys., 11, 2161-2177, doi:10.5194/acp-11-2161-2011, 2011.

Poole, L. R. and McCormick, M. P.:, Airborne lidar observations of Arctic polar stratospheric clouds: Indication of 
two distinct growth stages, Geophys. Res. Lett., 15, 21-23, doi:10.1029/GL015i001p00021, 1988.

Shibata, T., Shiraishi, K., Adachi, H., Iwasaka, Y., and Fujiwara, M.: On the lidar-observed sandwich structure of polar stratospheric clouds (PSCs): 1. Implications for the mixing state of the PSC particles, J. Geophys. Res., 104, 603-621, 1999.

Simmonds, I. and Keay, K.: Mean Southern Hemisphere extratropical cyclone behavior in the 40-year NCEP-NCAR reanalysis, J. Clim., 13, 873-885, doi:10.1175/1520-04422000013, 2000.

Simmonds, I., Burke, C., and Keay, K.: Arctic Climate Change as Manifest in Cyclone Behavior, J. Climate, 21, 5777-5796, 2008.

Stetzer, O., Möhler, O., Wagner, R., Benz, S., Saathoff, H., Bunz, $\mathrm{H}$., and Indris, O.: Homogeneous nucleation rates of nitric acid dihydrate (NAD) at simulated stratospheric conditions - Part I: Experimental results, Atmos. Chem. Phys., 6, 3023-3033, doi:10.5194/acp-6-3023-2006, 2006.

Teitelbaum, H., Moustaoui, M., and Fromm, M.: Exploring polar stratospheric cloud and ozone minihole formation: The primary importance of synoptic-scale flow perturbations, J.Geophys. Res., 106, 28173-28188, doi:10.1029/2000JD000065, 2001.
Voigt, C., Schreiner, J., Kohlmann, A., Zink, P., Mauersberger, K., Larsen, N., Deshler, T., Kröger, C., Rosen, J., Adriani, A., Cairo, F., Donfrancesco, G. D., Viterbini, M., Ovarlez, J., David, C., and Dörnbrack, A.: Nitric Acid Trihydrate (NAT) in polar stratospheric clouds, Science, 290, 1756-1758, 2000.

Wang, Z., Stephens, G., Deshler, T., Trepte, C., Parish, T., Vane, D., Winker, D., Liu, D., and Adhikari, L.: Association of Antarctic polar stratospheric cloud formation on tropospheric cloud systems, Geophys. Res. Lett., 35, L13806, doi:10.1029/2008GL034209, 2008.

Winker, D. M., Hunt W. H., and Matthew, J. M.: Initial performance assessment of CALIOP, J. Geophys. Res., 34, L19803, doi:10.1029/2007GL030135, 2007.

Yin, J. H.: A consistent poleward shift of the storm tracks in simulations of 21 st century climate, Geophys. Res. Lett., 32, L18701, doi:10.1029/2005GL023684, 2005. 